\title{
High-reflective Mulching Membrane for a Sustainable Development: Monitoring Campaign
}

\author{
Mattia Manni ${ }^{1}$, Alessia Di Giuseppe ${ }^{1}$, Alessandro Petrozzi ${ }^{1}$, Andrea Nicolini $^{2}$, Federico \\ Rossi $^{2}$, Franco Cotana ${ }^{2}$ \\ ${ }^{1}$ CIRIAF Inter-University Research Centre, 06125 Via Goffredo Duranti 67, Italy \\ ${ }^{2}$ Department of Engineering, University of Perugia, 06125 Via Goffredo Duranti 93, Italy
}

\begin{abstract}
Modern agriculture techniques are responsible for the production of large volumes of greenhouse gases that represent the main cause of climate change. At the same time, agricultural activities are negatively affected by climate change effects, showing a reduction in productivity. Within this framework, the present study aims at investigating the effectiveness of an innovative high-reflective mulching membrane that can be exploited in the agricultural sector to mitigate its environmental impact. It consists of a mulching membrane coupled to an irrigation system, and painted with bright pigments on the side facing the skydome. This technology was used in food crop farming in the experimental field in Perugia. Sensors for monitoring solar irradiation, rainwater recovery, and phenological parameters were installed. Data collected during the monitoring campaign conducted in summer demonstrated that the high-reflective membrane was capable to increase the ground solar reflectance up to 0.60 , while avoiding the utilization of potable water and water from the aquifer to irrigate the crops. An acceleration of the photosynthesis processes was also observed along with an increment in the productivity: tomatoes grew up to $20 \%$ more in weight.
\end{abstract}

\section{Introduction}

The raising of urban temperatures, the melting of glaciers, and the growing number of drought and flood events are only the most evident consequences of currently on-going climate changes [1]. Human-induced warming reached almost $1{ }^{\circ} \mathrm{C}$ above pre-industrial levels during 2017, and the overwarming phenomenon has been already experienced by up to $40 \%$ of the global population. National governments promoted agricultural and economic policies and measures for mitigating the amount of greenhouse gases (GHG) which are released in the atmosphere, thus reducing the frequency of such disaster events.

In 2018, the European Member States achieved the reduction target expected for 2020 ( $20 \%$ reduction from 1990 levels). However, the GHG emission trend projections highlighted that current policies and measures can deliver a $30 \%$ reduction by 2030 . Such an amount falls short from the $40 \%$ reduction target for 2030 [2]. Therefore, additional 
measures are necessary, and further efforts have to be made to enhance these projection trends.

Although agriculture has contributed to the positive trend in GHG emissions since the 1990 s, it still represents one of the most impacting sectors in Europe ( $6^{\text {th }}$ in this ranking) [2]. As a matter of facts, the impact on global GHG emissions of the agro-food chain accounts for up to $30 \%$ [3]. Several studies in the Literature have determined how various food crops contributed to this percentage: roots such as onions $\left(0.17 \mathrm{kgCO}_{2 \text {-eq }} \mathrm{kg}^{-1}\right)$, potatoes $\left(0.18 \mathrm{kgCO}_{2 \text {-eq }} \mathrm{kg}^{-1}\right)$, and carrots $\left(0.20 \mathrm{kgCO}_{2 \text {-eq }} \mathrm{kg}^{-1}\right)$ showed the lowest $\mathrm{GHG}$ emissions amount along with vegetables $\left(0.37 \mathrm{kgCO}_{2 \text {-eq }} \mathrm{kg}^{-1}\right)$ and fruits $\left(0.42 \mathrm{kgCO}_{2 \text {-eq }} \mathrm{kg}^{-}\right.$ $\left.{ }^{1}\right)$, while seeds like sunflowers $\left(1.41 \mathrm{kgCO}_{2 \text {-eq }} \mathrm{kg}^{-1}\right)$ were characterized by the greatest environmental impact together with wheat and pulses (around $0.50 \mathrm{kgCO}_{2-\mathrm{eq}} \mathrm{kg}^{-1}$ ) [3-5]. Also, modern agriculture techniques are responsible for the production of large volumes of GHG which represent the main cause of on-going climate changes. At the same time, climate changes negatively affect agricultural activities causing a reduction in crop productivity and significant economic losses [6-8].

Within this framework, new and more sustainable technologies such as mulching membranes, advanced irrigation systems, water recovery plants, and high-efficiency greenhouse infrastructures were investigated by the scientific community to enhance the growth process as well as the yield of food crops $[9,10]$. The present study proposes an innovative application of high-reflective materials to the mulching membrane technology. A mulching membrane capable of reflecting backward the solar irradiation without altering its wave-length was applied to the experimental field realized in the university campus of the Department of Engineering in Perugia. Its contribution to the increment of the ground solar reflectance as well as its influences on the growth cycle of crops were investigated.

High-reflective materials represent a potential solution to reduce global temperature after around 20 years from their application [11]. Numerous studies demonstrated the key role they played in enhancing the comfort levels within different urban contexts in both indoor and outdoor environments [12-14]. Also, they can contribute to lowering buildings' energy consumption throughout the year [15]. However, there are also some issues related to the exploitation of high-reflective coatings in densely built environments such as the increasing of inter-building reflections [16-18]. It generally led to the increment of solar irradiation amounts trapped in the urban corridors, thus nulling the cooling effects from high-reflective materials. As a matter of facts, these treated surfaces reflect solar irradiation in a Lambertian diffuse way by orienting the reflected fraction mainly towards the close buildings. In order to overcome this limitation, retro-reflective materials were introduced as a sub-group of the high-reflective ones [19]. Such materials couple the high solar reflectance coefficient to the capacity of directing the reflected rays towards the source and beyond the urban canyon boundaries. The retro-reflective materials investigated in this study consist of a layer of glass microspheres which is added to the membrane on the side exposed to sunlight.

\section{Methodology}

\subsection{Workflow}

The hereby study proposed a high-reflective mulching membrane which can be exploited to reduce the GHG emissions from the agricultural sector as well as to improve the food crops farming. The workflow followed in this research was arranged in three main stages (Figure 1): design of experiment, monitoring campaign, and data assessment. 


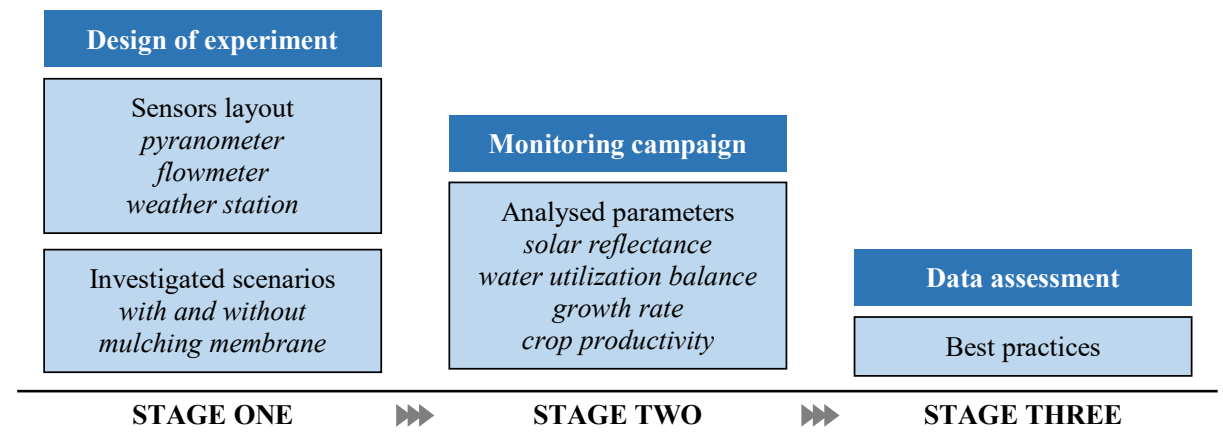

Figure 1. Overview of the three-stages workflow followed in this research study.

Firstly, an experimental field was realized in the Engineering University Campus in Perugia. It was arranged in two sections: the proposed membrane covered the one, while traditional techniques were used in the other. Then, the food crop to be cultivated was selected among the ones characterized by high yields and low environmental impacts. Principles of the Mediterranean diet were also taken into account. Mediterranean diet, which was mentioned among the most sustainable diets by the Food and Agriculture Organization of the United Nations in 2010, is capable of coupling nutrients balancing and health products with local food production and biodiversity protection. Finally, the cluster of parameters to be monitored was determined and the layout of the sensors was designed. In particular, data concerning the irradiation reflected upwards, the rainwater recovering, and the phenological parameters of the crops were collected in this monitoring campaign.

Secondly, the monitoring campaign was conducted and the aforementioned parameters were controlled in the two field configurations. The quantities reported in this study referred to summer climate conditions when it came to phenological features and rainwater management, while referring to the winter season when it came to solar analyses. In particular, measures of the surface solar reflectance were collected with a clear sky during two representative days. On the contrary, the rainwater recovering and also the phenological parameters were assessed throughout the whole duration of the July month.

Thirdly, the effectiveness of the proposed approach to farming activities was evaluated through a comparison of the outcomes from the two sections of the experimental field.

\subsection{High-reflective Mulching Membrane Concept}

The advanced mulching membrane (Figure 2) which was exploited in the experimental field was here described. Such a technology consists of a mulching membrane that was treated with bright pigments on the side exposed to solar irradiation. Also, a layer of glass micro-spheres was applied over this painting in order to implement a retro-reflective behavior in addition to the high-reflective properties. It would permit cooling the soil and increasing the solar accessibility of the plants, with positive effects on their photosynthesis process.

Alongside these, the investigated mulching membrane can guarantee some advantages in terms of water management as well. As a matter of facts, the membrane surface is less permeable to water than the soil by allowing collecting rainwater during the precipitation events, throughout the year. Such volumes of rainwater are stored into a 5,000 1 tank and finally delivered to the crops through the drip sub-irrigation system integrated into the mulching membrane. This system could permit to optimize the irrigation stage by consuming lower volumes of water and reducing the exploitation of potable water and water from the aquifer. 


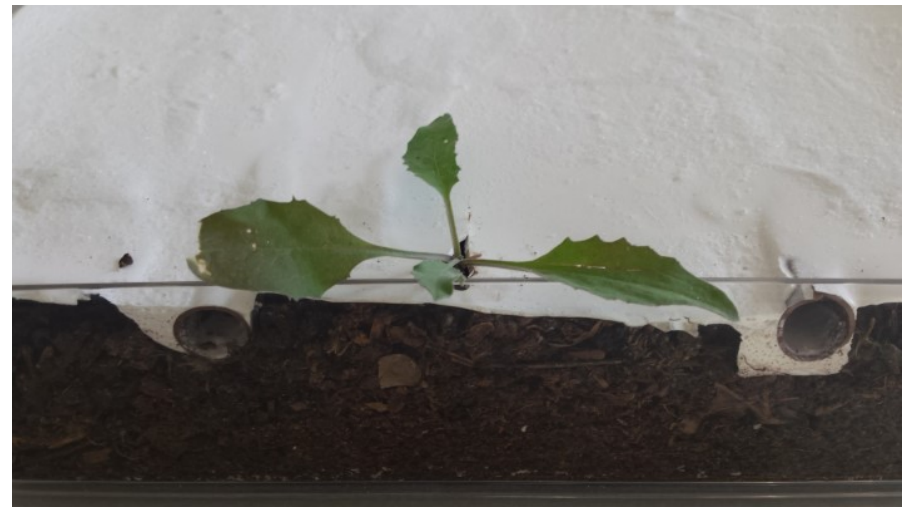

Figure 2. Transversal section view of the high-reflective mulching membrane structure.

\subsection{Experimental Field and Sensors Layout}

The experimental field that was installed in Perugia is $100 \mathrm{~m}^{2}$ large. The field surface is slightly tilted towards south-east in order to make easier the rainwater collection (Figure 3). It is located in an unobstructed context and the ground is well irradiated without relevant shading phenomena. The area is arranged in 12 rows along with whom food crops are cultivated. Up to10 rows were covered by the high-reflective mulching membrane and correspond to the enhanced scenario here investigated. In this sector, the irrigation system was integrated into the membrane device, while in the other rows a traditional drip irrigation system was installed.

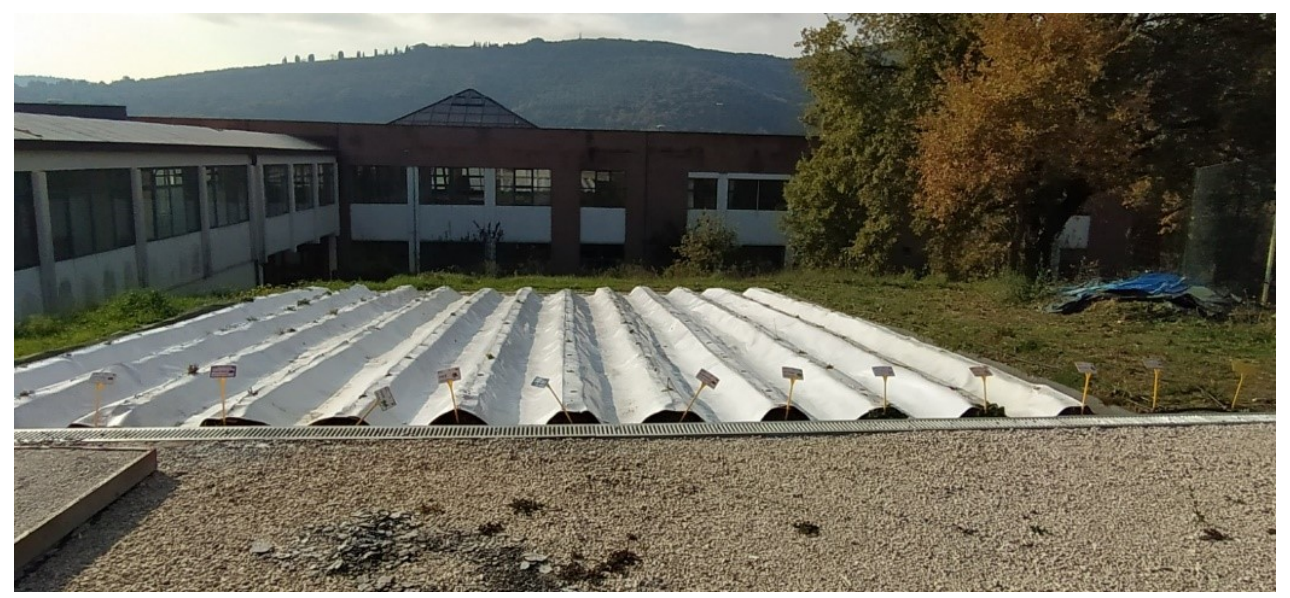

Figure 3. Experimental field in the Engineering University Campus in Perugia before starting the cultivation of the crop.

An overview of the monitored parameters along with the respective units of measurement and the period of the year when data were collected was presented in Table 1.

When it comes to the sensors, the experimental field was equipped with various instruments for controlling and measuring the incident solar irradiation, the volume of rainwater, the amount of water supplied to the field, the membrane surface temperature, the phenological parameter of the crops, and humidity and temperature of the soil. However, in the present study, only data concerning solar irradiation, rainwater recovering, and crops growing cycle were reported and assessed. 
Table 1. Overview of the monitored parameters.

\begin{tabular}{|c|c|c|c|}
\hline Analysis & Parameter & $\begin{array}{c}\text { Unit of } \\
\text { measurement }\end{array}$ & Monitored period \\
\hline Albedo assessment & Solar reflectance & - & $\begin{array}{c}27^{\text {th }} \text { December } \\
10^{\text {th }} \text { January }\end{array}$ \\
\hline \multirow{3}{*}{ Water management } & Rainfall event magnitude & {$[\mathrm{mm}]$} & July \\
\hline & Collected water volume & {$\left[\mathrm{m}^{3}\right]$} & July \\
\hline & Supplied water volume & {$\left[\mathrm{m}^{3}\right]$} & July \\
\hline \multirow{2}{*}{ Phenological analysis } & Growth indices & - & June-July \\
\hline & Crop production & {$[\mathrm{kg}]$} & June-July \\
\hline
\end{tabular}

A four-component net radiometer* (equipped with Second class WMO pyranometers) was placed one meter above the ground level to determining the fraction of solar irradiation reflected by the soil and the membrane. Also, a drone equipped with a pyranometer was exploited for measuring the reflected irradiation at various altitudes ranging from one meter to one hundred meters.

Flow meters (DN50 ${ }^{\dagger}$ with an accuracy of $0.5 \%$ ) were installed upstream and downstream of the irrigation system, and coupled to the rain gauge (PMB2* sensor with a resolution of $0.2 \mathrm{~mm}$ of rain). In this way, the volume of rainfall is measured as well as the volume of water supplied to the food crops. Then, the recovered rainwater was calculated as the difference between these amounts.

The phenological parameters were defined according to the food crop selected for being cultivated. This part of the monitoring campaign was conducted throughout the whole crop's growing cycle, in summer. The considered growth stages were: (i) cotyledon leaves emission, (ii) leaves development, (iii) flowers emission (or fluorescence), (iv) flowering, and (v) fructification. Results consist of a cluster of indices composed of two numbers which respectively referred to the stage of the plant life-time (i.e. cotyledon leaves emission, leaves development, flower emission, flowering, and fructification) and the development of stage development (i.e. beginning, peak). Hence, the first number varies between one and five, while the second can be equal to zero (stage beginning) or five (stage peak). An overview of the considered indices was reported in Table 2.

Table 2. Indices utilized for defining the different stages of the crop growth cycle.

\begin{tabular}{|l|l|}
\hline Index & Growth cycle stage \\
\hline 10 & Cotyledon leaves emission \\
\hline 20 & First leaf appearance (beginning of the leaves development) \\
\hline 25 & Peak of leaves development \\
\hline 30 & Flowers emission (or florescence) \\
\hline 40 & First flowers appearance (beginning of the flowering) \\
\hline 45 & Peak of flowering \\
\hline 50 & First fruit appearance (beginning of the fructification) \\
\hline
\end{tabular}

The sensors layout was completed by thermocouples (measuring the temperature) that were placed in the proximity of the first line of each row. Data about the temperature were collected at three different heights: (i) $0.10 \mathrm{~m}$ above the ground, (ii) at the ground level, and (iii) $0.10 \mathrm{~m}$ below the ground (thermocouples were buried into the soil). When it came to the field sector covered by the mulching membrane, sensors at ground level were placed on the membrane side which is exposed to solar irradiation. Also, the chlorophyll sensors were

\footnotetext{
*www.1si-lastem.it/webdocument/BLT_01084_en.pdf

$\dagger$ www.measureit.it/misuratore-di-portata-dn50.html

$\$$ www.cae.it/upload/products/pdf/pmb2/Rain_Gauge_PMB2.pdf
} 
applied to the plants to evaluate the effects of the mulching membrane on the photosynthesis processes as well as on the productivity of the crop.

\subsection{Preliminary Food Crop Selection}

The food crop which was selected to investigate the effectiveness of the high-reflective membrane technology was Solanum Lycopersicum L. (hereinafter referred to as "tomato"). As a matter of facts, the tomato was the first in the Italian ranking of vegetable crops $^{\S}$ in terms of yield by achieving up to 5,798,100 $\mathrm{t} \mathrm{ha}^{-1}$. In addition to this, the tomato was also classified by Clune [3] as a low-carbon crop with a carbon footprint as high as $0.51 \mathrm{kgCO}_{2}$ eq $\mathrm{kg}^{-1}$. Tomato is probably the most popular and consumed local food crop in Italy that plays a key role in enriching the human diet with vitamins (i.e. vitamin A, vitamin $\mathrm{C}$ ), minerals (i.e. calcium, potassium), bioactive components (i.e. lycopene), and dietary fiber. The selected food crop was cultivated in both the sections of the experimental field (Figure 4) in order to compare the monitored parameters and determinate the influences on plants' growth cycle of the high-reflective mulching membrane.
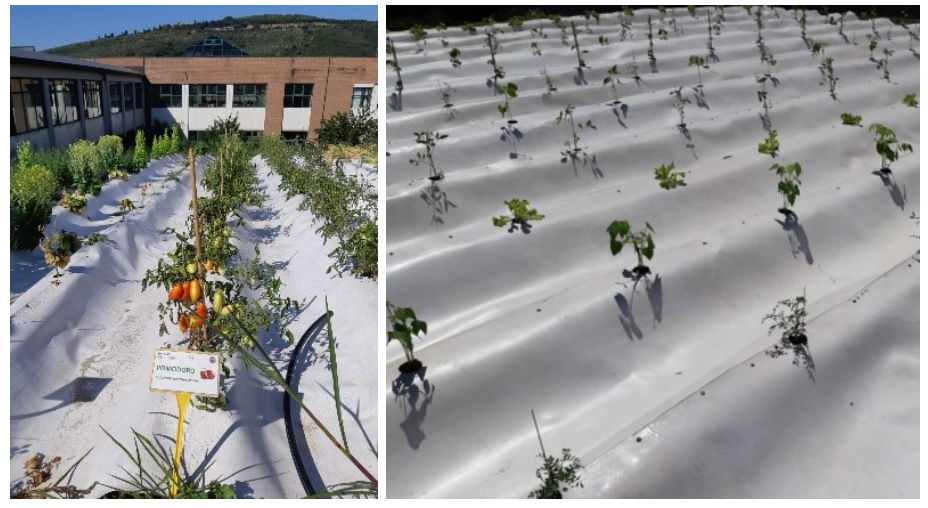

Figure 4. Plants of tomatoes cultivated in the experimental field.

\section{Results and discussion}

Results reported and discussed in this section were arranged in three paragraphs which concern, respectively, solar reflectance assessment, water recovery, and phenological analyses.

Data collected about the surface solar reflectance were reported in Figure 5 for the $27^{\text {th }}$ December and the $10^{\text {th }}$ of January. Each series of values described a specific trajectory of the drone (i.e. ascent, descent). On the $27^{\text {th }}$ December, the drone was located above the high-reflective mulching membrane and it reached 14.0 meters of altitude. The measured solar reflectance quantities varied between 0.65 ( $0.5 \mathrm{~m}$ above the field) and $0.25(14.0 \mathrm{~m}$ above the field). Similar amounts were observed on the $10^{\text {th }}$ January when the drone flying up to 90.0 meters above the field measured solar reflectance quantities ranging from 0.70 (1.5 $\mathrm{m}$ above the field) to 0.20 (90.0s $\mathrm{m}$ above the field). The spatial distribution highlighted that the solar reflectance measured by the pyranometers installed on the drone was strongly influenced by both the trajectory of the drone itself (different measures at the same height) and the height of the sensors (different measures at different height). As a matter of facts, the drone was not perfectly parallel to the ground and it was (slightly) tilted

\footnotetext{
$\S$ www.fao.org/faostat
} 
according to the executed maneuver and wind magnitude (which varied depending on the height). Changes in the position of the pyranometers caused such differences in measured quantities, although the flight altitude was unaltered. Also, the different altitudes of the flight caused the inclusion in the monitored zone of a wider area which also presented optical properties different from the high-reflective mulching membrane. Outcomes demonstrated that the high-reflective mulching membrane was capable of almost triplicating the ground solar reflectance (from 0.25 to 0.65 ) while reducing the absorbed fraction of incident solar irradiation.
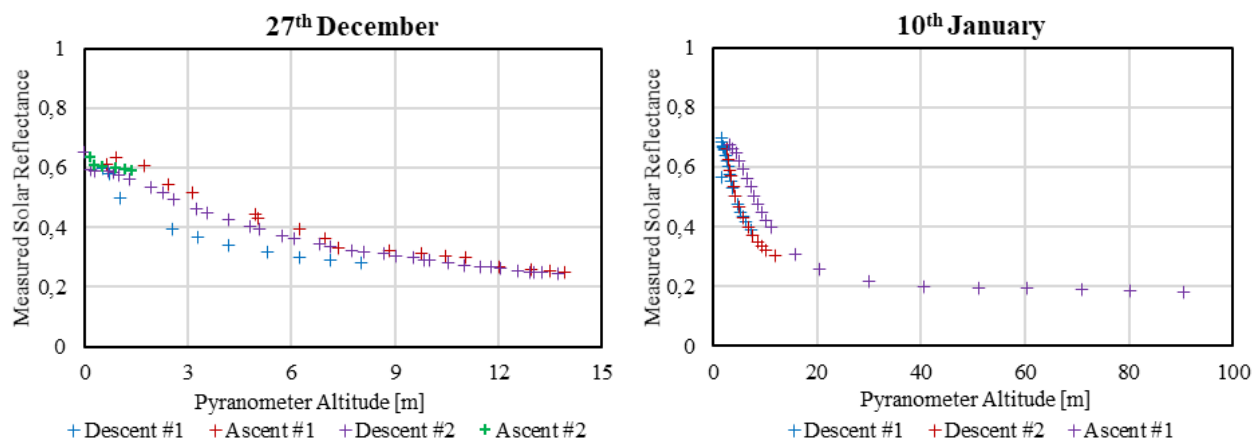

Figure 5. Distribution of the measured solar reflectance values depending on pyranometer altitude.

Results from the phenological monitoring campaign were reported for the reference case and the enhanced scenario in Figure 6. The blue bars define the range of values for growth indices which were observed in food crops during a specific day (highest and lowest values), while the black horizontal lines correspond to the geometric mean numbers. It was observed that the crops cultivated with the mulching membrane were capable of producing fruits earlier than crops from the reference case, although the latter showed higher growth rates at the very beginning. All the plants in the reference case presented a significant number of leaves from the third monitored day, while the others only achieved this stage in the seventh.
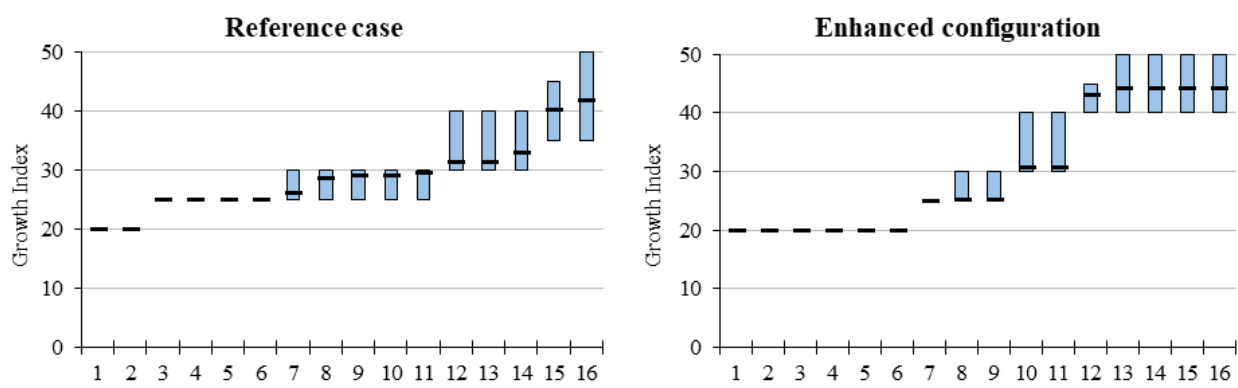

Figure 6. Growth cycle of the investigated crops in the reference case and the enhanced configuration.

When all the plants reached the growth level 50 (first fruit appearance), the plant productivity was utilized as a key performance indicator for comparing the two field configurations. Plants covered by the high-reflective mulching membrane produced up to $5,700 \mathrm{~g}$, almost $1,000 \mathrm{~g}$ more than the reference plants (Figure 7). Thus, the proposed farming technology permitted increasing the productivity of crops by around $20 \%$ if compared to traditional techniques. 


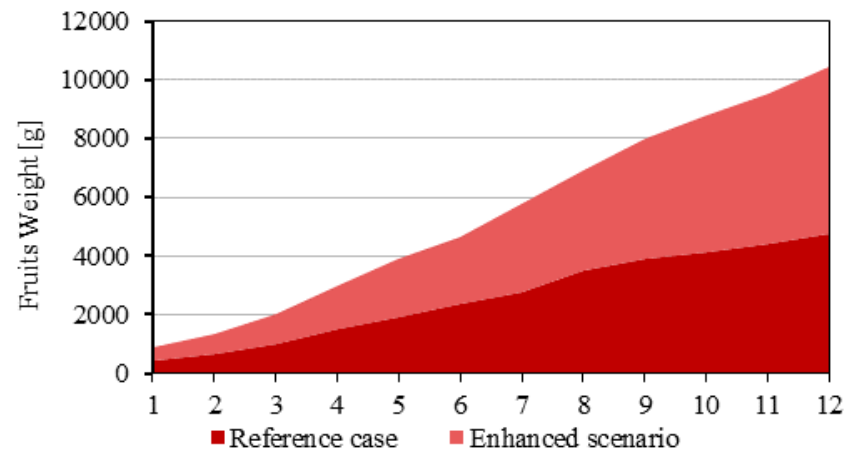

Figure 7. Trend of crop productivity in terms of fruit weight.

When it came to the water management, in this paragraph were reported the collected data referring to the number and magnitude of rainfall events, and also the volume of rainwater collected by the membrane, stored into the tank, and finally delivered to the crops. During July, up to three significant precipitation events were observed as described in Figure 8. The most intense showed a rainfall thickness equal to $83 \mathrm{~mm}$ and permitted to store in the tank a volume of recovered water of around $8 \mathrm{~m}^{3}$. In total, $125 \mathrm{~mm}$ of rain felt in this month and around $12 \mathrm{~m}^{3}$ of water was collected through the $100 \mathrm{~m}^{2}$ wide membrane surface.

When it came to the drip sub-irrigation plant which was integrated into the membrane, it was activated two times per day for a global duration of 30 minutes. A daily volume of water as high as $0.2 \mathrm{~m}^{3}$ was delivered to the crops throughout the $120 \mathrm{~m}$ long pipelines equipped with 400 drippers (every $0.30 \mathrm{~m}$ ). During the monitored month, a total amount of $6 \mathrm{~m}^{3}$ of recovered rainwater was utilized for irrigating the crops. The balance between the collected rainwater (positive contributions) and the water exploited in farming activities (negative contributions) was described in Figure 8. Outcomes demonstrated that the storage system permitted to avoid using potable water and water from an aquifer which is rich in calcium and other minerals capable of obstructing dripper components and reducing the life-time of the sub-irrigation plant.

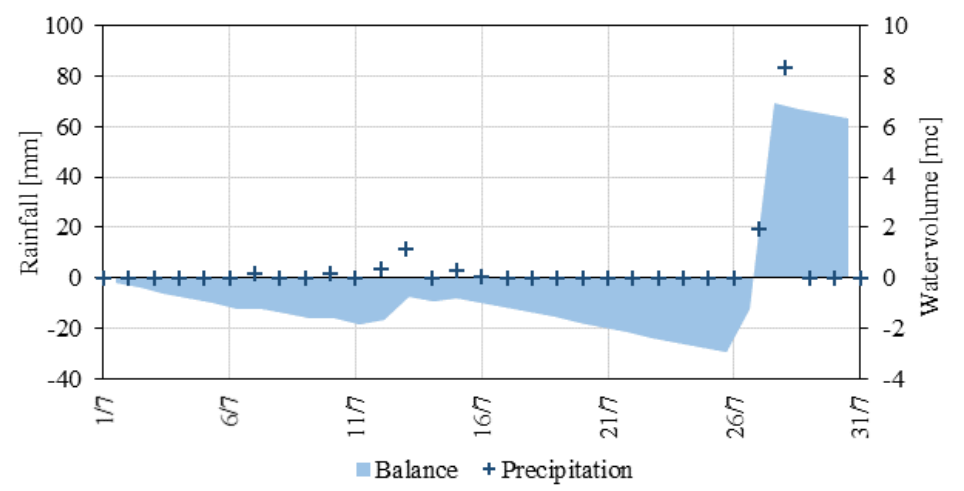

Figure 8. Daily trend of precipitation events and water balance of the experimental field.

\section{Conclusions}

The effectiveness of an innovative mulching membrane enhanced with high-reflective pigments and integrated with a drip sub-irrigation system was investigated in this research 
study. The influences of this technology on the albedo of the ground, on crop productivity, and also on water utilization were assessed through a monitoring campaign conducted in the experimental field in Perugia. Advantages related to the cultivation of tomatoes as representatives of the Mediterranean diet were determined. Collected data demonstrated that the high-reflective mulching membrane can improve crop productivity with reduced water consumption. Furthermore, the improved solar reflectance permitted retro-reflecting most of the incident irradiation contributing to global warming effects mitigation, in the long term.

The main findings are summarized on the following points:

- Solar reflectance of the experimental field was increased from 0.20 to 0.60 (measured at one meter above the ground);

- Productivity of the rows was incremented by around $20 \%$;

- The utilization of potable water and water from the aquifer for irrigation activities was nulled.

The monitoring campaign described in this study represented an opportunity for evaluating the design of the experiment defined in the first research stage. The considered parameters permitted to preliminary assess the effectiveness of the mulching membrane, but including also the soil temperature and humidity, and the chlorophyll flow would allow to provide a more complete overview of the technology's influences. Such data will be included in the next campaign. Also, the effects due to the mulching membrane application will be investigated during the winter season, and other food crops will be cultivated together with tomatoes in order to outline a sustainable and healthy diet based on the optimized and fair exploitation of natural resources.

Further analyses can be carried out to integrate results presented in this research study and to identify the nutritional and organoleptic properties of food crops. The characterization of food crops from this point of view will permit us to evaluate other effects of the high-reflective mulching membrane by examining in detail the plants' growing cycle.

\section{References}

1. R. K. Pachauri and L. A. Meyer, IPCC, 2014: Climate Change 2014: Synthesis Report. Contribution of Working Groups I, II and III to the Fifth Assessment Report of the Intergovernmental Panel on Climate Change (Geneva, Switzerland, 2014).

2. European Environment Agency, Total Greenhouse Gas Emission Trends and Projections in Europe (Copenhagen, 2019).

3. S. Clune, E. Crossin, and K. Verghese, J. Clean. Prod. 140, 766 (2017).

4. T. Garnett, Fruit and Vegetables \& UK Greenhouse Gas Emissions: Exploring the Relationship (2006).

5. F. Caracciolo, G. Cicia, T. Del Giudice, I. Menna, and L. Cembalo, Proc. Syst. Dyn. Innov. Food Networks 2012 14, 96 (2013).

6. A. Tukker and B. Jansen, J. Ind. Ecol. 10, 159 (2006).

7. Y. Vitasse, A. Bottero, M. Cailleret, C. Bigler, P. Fonti, A. Gessler, M. Lévesque, B. Rohner, P. Weber, A. Rigling, and T. Wohlgemuth, Glob. Chang. Biol. 25, 3781 (2019).

8. Q. Ma, J.-G. Huang, H. Hänninen, and F. Berninger, Glob. Chang. Biol. 25, 351 (2019).

9. A. I. Hudu, K. N. Futuless, and N. A. Gworgwor, J. Sustain. Agric. 21, 37 (2002).

10. M. Mahmood, K. Farooq, H. Amjad, and S. Raham, Asian J. Plant Sci. 2, (2002).

11. M. Manni, A. Petrozzi, V. Coccia, A. Nicolini, and F. Cotana, J. Build. Eng. 31, 101340 (2020). 
12. M. Manni, G. Lobaccaro, F. Goia, A. Nicolini, and F. Rossi, Sol. Energy 189, 74 (2019).

13. J. Yuan, K. Emura, C. Farnham, and H. Sakai, Build. Environ. 105, 140 (2016).

14. F. Rossi, B. Castellani, A. Presciutti, E. Morini, E. Anderini, M. Filipponi, and A Nicolini, Energy Build. 126, 340 (2016).

15. C. Piselli, A. L. Pisello, M. Saffari, A. de Gracia, F. Cotana, and L. F. Cabeza, Energies 12, 3354 (2019).

16. A. L. Pisello, V. L. Castaldo, J. E. Taylor, and F. Cotana, Energy Build. 76, 513 (2014).

17. A. L. Pisello, J. E. Taylor, X. Xu, and F. Cotana, Build. Environ. 58, 37 (2012).

18. M. Manni, G. Lobaccaro, F. Goia, and A. Nicolini, Sol. Energy 176, 194 (2018).

19. F. Rossi, A. L. Pisello, A. Nicolini, M. Filipponi, and M. Palombo, Appl. Energy 114, 621 (2014). 